\title{
Changes of ocular surface CD14 and TLR- 4 and TLR-9 in patients with Vernal keratoconjunctivitis: an inflammatory epiphenomenon or a novel pathogenic mechanism?
}

\author{
marta sacchetti ${ }^{1}$, Marcella Nebbioso ${ }^{2}$, marco segatto $^{1}$, irene abicca ${ }^{1}$, Alice Bruscolini ${ }^{1}$, \\ Anna Maria Zicari ${ }^{3}$, and Alessandro Lambiase ${ }^{1}$ \\ ${ }^{1}$ University Sapienza of Rome \\ ${ }^{2}$ Policlinico Umberto I \\ ${ }^{3}$ Policlinico Umberto 1 Roma
}

July 23, 2020

\begin{abstract}
Background: CD14 is involved in the modulation of immune reaction via toll-like receptors (TLR) and may influence the development of allergic diseases. The role of CD14 in vernal keratoconjunctivitis (VKC) has not yet been investigated. The aim of this study is to evaluate changes of tear soluble sCD14 and conjunctival CD14, TLR-4 and 9 expression in patients with VKC in the active and quiescent phases. Methods: 18 patients with VKC during active inflammation (group A, N=9), in the quiescent phase (group Q, N=5) and after recovery (group $\mathrm{R}, \mathrm{N}=4$ ) and 10 healthy subjects were included. Patients in group A were treated with corticosteroid eye drops 4 times daily for 7 days. Expression of sCD14 in tears and of CD14, TLR-4, and TLR-9 by conjunctival epithelium were evaluated by Western Blot in all groups and after corticosteroid treatment. Results: expression of sCD14 and of CD14, TLR-4 and TLR-9 was significantly decreased in group A when compared with healthy subjects and with VKC group Q and R. Lower expression of sCD14, CD14, TLR-4 and TLR-9 were significantly correlated with the severity of papillary reaction, while the lower sCD14 was correlated with severity of conjunctival hyperemia. Conjunctival expression of TLR-4, but not sCD14, CD14 and TLR-9, was significantly reduced after topical corticosteroid treatment. Conclusion: tear sCD14, and conjunctival CD14, TLR4 and TLR-9 decreased during ocular surface inflammatory reaction in patients with VKC. CD14 and TLRs may represent potential therapeutic targets, although it requires further studies.
\end{abstract}

\section{Introduction}

Vernal keratoconjunctivitis (VKC) is a chronic, allergic disease of the cornea and conjunctiva, mostly affecting boys in pre-pubertal age. ${ }^{1,} 2$ Patients with VKC experience recurrent flare-ups of ocular surface inflammation, characterized by intense symptoms of photophobia, redness and secretion, often associated with corneal involvement and impairment of visual function and decrease of quality of life. ${ }^{1,3-5}$

Several studies demonstrated that ocular surface inflammation in VKC is characterized by a T-helper cells type 2 (Th2)-driven allergic reaction, associated with conjunctival infiltration of mast cells, eosinophils and CD4 lymphocytes. ${ }^{6}{ }^{7}$ However, the immunopathogenesis of VKC has not been completely understood. ${ }^{2}$ Recent evidence demonstrated a role of the innate immunity in the pathogenesis of VKC, including changes of conjunctival expression of toll-like receptors (TLRs) 2,4 and $9 .^{8-10}$ TLRs are a family of pattern-recognition receptors expressed by resident and immune cells, which recognize microbial compounds such as lipopolysaccharide (LPS), endotoxins, CpG-DNA and Poly(I:C)/double-stranded RNA. ${ }^{11}$ Different findings demonstrated that TLRs requires additional proteins to be stimulated by their ligands. ${ }^{12}$ Among them, the role of CD14 as ligand of TLR-4 and TLR-9 has been demonstrated. ${ }^{13}$ CD14 is a multifunctional receptor expressed 
by resident and immune cells in a membrane-bound form and it also exists as a soluble form (sCD14). ${ }^{14}$ It has been shown that CD14 and TLRs binding with microbial compounds activates adaptive immune T-helper type 1 (Th1) response, by inducing production and release of cytokines such as IL-1, IL-12, TNF- $\alpha$, IL- 6 and IL-8. ${ }^{11,12,15-17}$ Alterations of sCD14 and CD14 in allergic conditions such as asthma, has been previously described. ${ }^{17}$ The role of TLRs in the pathogenesis of ocular surface diseases has been extensively studied. ${ }^{8}$ An experimental study in a model of allergic conjunctivitis demonstrated that TLR-4 stimulation by LPS suppressed Th2-associated allergic response, suggesting a role of TLR-4 and CD14 in the development of allergic conjunctivitis. ${ }^{18}$ In humans, the presence of CD14 has been described in cornea and conjunctival epithelial cells and sCD14 in tears of healthy subjects, but not in allergic diseases. ${ }^{19}$

Therefore, the aim of this study is to investigate the involvement of tear sCD14 and conjunctival CD14 in patients with VKC. Specifically, expression of sCD14 in tears and of CD14, TLR4 and TLR9 in conjunctival epithelium was assessed in patients with VKC in the quiescent phase and during flare-ups of ocular inflammation before and after topical corticosteroid treatment.

\section{Material and Methods}

Eighteen patients with VKC were included in this study: (i) during active inflammation (group A), (ii) during quiescent phase (group Q) and after recovery of VKC (group R). Ten healthy subjects were included as control group. The study was performed at the Department of Sense Organs and Department of Pediatrics at Sapienza University of Rome, following the tenants of the Declaration of Helsinky. Informed consent was signed by all participants and caregiver, and the study was approved by the Ethic Committee of University Sapienza of Rome.

Diagnosis of VKC was based on clinical history and clinical presentation. ${ }^{4}$ Patients with VKC were included in different groups: (i) Active group: presence of persistent ocular symptoms associated with moderate to severe conjunctival hyperemia and secretion and presence of corneal involvement; (ii) quiescent group: absence or mild and intermittent ocular symptoms, absence of conjunctival hyperemia and of corneal involvement; (iii) recovery group: history of VKC with absence of symptoms and signs of inflammation from at least 1 year. ${ }^{4,20}$ All patients did not use antiallergic topical and systemic treatments from at least 7 days.

At baseline visit, clinical history including skin prick test results was collected and the presence of ocular signs and symptoms of VKC was investigated. Specifically, the presence and severity of conjunctival hyperemia and secretion, limbal and upper tarsal papillary reaction was evaluated by slit lamp examination and scored from 0 to 3 ( 0 =absence, $1=$ mild, $2=$ moderate and $3=$ severe). ${ }^{3,4}$ Corneal epithelial damage was evaluated by fluorescein vital staining and scored by Oxford scale. ${ }^{21}$ Patients were asked for the presence of symptoms of such as itching, tearing and photophobia. Symptoms were scored from 0 to 3 ( $0=$ absence, $1=$ mild, $2=$ moderate and $3=$ severe).

Conjunctival impression cytology and tear samples were collected in both eyes of VKC and healthy subjects. ${ }^{22}{ }^{23}$ Patients included in group A which received treatment with Hydrocortisone (Cortivis eye drop, Medivis S.r.l., Catania, Italy) eye drops 4 times daily for 7 days. At the end of treatment period patients were evaluated as described above and tear and conjunctival samples were collected.

Tear samples were collected by imbibition of sterile Sharp-tip Microsponges (Alcon Lab. Inc., Fort Worth, TX) gently placed at the inferior conjunctival fornix and removed after 30 seconds. Tears were collected by centrifugation at $13000 \mathrm{rpm}$ for 3 minutes and stored at $-20^{\circ} \mathrm{C} .{ }^{22}$ Conjunctival impression cytology was performed after tear collection in both eyes by applying a sterile cell culture insert (Millicell-CM, $0.4 \mu \mathrm{m}, \varnothing$ $12 \mathrm{~mm}$, Millipore) to the nasal and temporal bulbar conjunctiva, and then stored at $-20^{\circ} \mathrm{C} .{ }^{24}$

Western blot analysis was performed on biological samples to evaluate tear sCD14 and conjunctival epithelium CD14, TLR-4 and 9.

\section{Western blot analysis}

Proteins from tear samples and conjunctival impression cytology were obtained by sonication and centrifu- 
gation as previously described. ${ }^{24,}{ }^{25}$ Briefly, proteins were transferred onto nitrocellulose membrane by using Trans-blot turbo transfer system (Biorad Laboratories, Milan, Italy), membranes were then blocked with no fat dry milk (5\% in PBS-tween) for 1 hour at room temperature, and probed overnight with the following antibodies: anti-TLR9 (sc-25468, Santa Cruz Biotechnology, CA, USA), anti-TLR4 (sc-52962, Santa Cruz Biotechnology, CA, USA), anti-CD14 (sc-58951, Santa Cruz Biotechnology, CA, USA), and anti-actin (sc47778, Santa Cruz Biotechnology, CA, USA). The day after, following incubation with secondary anti-rabbit and anti-mouse antibodies (Biorad Laboratories, Milan, Italy), protein-bound antibodies were visualized by using chemiluminescence reaction with Clarity Western ECL substrates (Biorad Laboratories, Milan, Italy) and detected through Chemidoc Imaging System (Biorad Laboratories, Milan, Italy). Images derived from Western blots were analyzed with ImageJ software for Windows, and the ratio between the protein of interest and the correspondent housekeeping protein/Ponceau Red staining was calculated. Notably, actin was chosen as reference to normalize protein loading in conjunctival impression cytology, whereas sCD14 from tear samples was normalized by using Ponceau Red staining. Values are expressed as arbitrary units (a.u.).

\section{Statistical analysis}

Independent sample T-test was used to compare sCD14 tear levels, and CD14, TLR-4 and TLR-9 conjunctival expression between groups of patients with VKC and healthy subjects. Paired sample T-test was used to compare sCD14 tear levels, and CD14, TLR-4 and TLR-9 conjunctival expression before and after topical corticosteroid treatment in group A. Clinical parameters were correlated with CD14, TLR-4 and TLR-9 expression levels by Sperman rho test. (SPSS 18, IBM, Chicago: SPSS Inc). P values $<0.05$ were considered statistically significant.

\section{Results}

Eighteen patients with VKC (15 males and 3 females, mean age $10.7 \pm 5.7$ years) were included in the study. Ten healthy subjects (6 males, 4 females, mean age $8 \pm 3$ years) were included as control group. Nine patients with VKC ( 7 males, 2 females, mean age $9 \pm 2.3$ years) were in the active phase (group A) of VKC, 5 (4 males, 1 female, mean age $8.5 \pm 4.4$ years) were in the quiescent phase (group Q) and 4 patients (4 males, mean age $22 \pm 5$ years) were included in the recovery group (R). Eleven (61\%) out of 18 patients showed positive skin prick test for aeroallergens. Demographic and clinical characteristics of patients included in this study are summarized in Table 1.

Patients with VKC showed significant decrease of tear sCD14 expression when compared with healthy controls $(0.58 \pm 0.27$ a.u. vs $1 \pm 0.14$ a.u., $\mathrm{p}<0.001)$. By comparing the different groups, patients with VKC in the active phase showed a significant decrease of tear sCD14 (0.45 \pm 0.2 a.u.) when compared with healthy subjects $(\mathrm{p}<0.001)$ and with both VKC group $\mathrm{Q}(0.87 \pm 0.16$ a.u., $\mathrm{p}=0.005)$ and group $\mathrm{R}(1.1 \pm 0.13$, $\mathrm{p}<0.001)$. VKC group $\mathrm{Q}$ and group $\mathrm{R}(1.1 \pm 0.16)$ did not show significant changes when compared with healthy controls. (Figure 1A).

Conjunctival epithelium expression of CD14 showed similar results. In fact, conjunctival CD14 expression was significantly decreased in patients with VKC when compared with healthy subjects $(0.7 \pm 0.29$ a.u. vs $1 \pm 0.1$ a.u., $\mathrm{p}=0.013)$. Patients with VKC group A showed significant decrease of conjunctival CD14 (0.49 \pm 0.14 a.u.) when compared with healthy subjects $(\mathrm{p}=0.001)$ and with VKC in both group $\mathrm{Q}(1.02 \pm 0.58$ a.u., $\mathrm{p}<0.001)$ and $\mathrm{R}(1.18 \pm 0.02$ a.u., $\mathrm{p}<0.001)$. Patients with $\mathrm{VKC}$ in the quiescent phase and after VKC recovery did not show significant difference in conjunctival expression of CD14, when compared with healthy controls. (Figure $1 \mathrm{~B}$ )

Conjunctival epithelium expression of TLR-4 was significantly decreased in patients with VKC when compared with healthy controls $(0.4 \pm 0.27$ a.u. vs $1.06 \pm 0.07$ a.u., $\mathrm{p}<0.001)$, while conjunctival expression of TLR-9 did not show significant changes $(0.82 \pm 0.4$ a.u. vs $1 \pm 0.12$ a.u.). VKC patients in the active phase showed a significant decrease of both TLR- 4 and TLR-9 when compared with healthy controls (TLR-4: $0.17 \pm 0.03$ a.u., $\mathrm{p}=0.028$; TLR-9: $0.54 \pm 0.08$ a.u., $\mathrm{p}=0.011$ ) and with VKC group Q (TLR-4: $0.65 \pm 0.12$ a.u., $\mathrm{p}=0.004$; TLR-9: $1.3 \pm 0.12$ a.u., $\mathrm{p}<0001)$ and VKC group R (TLR-4: $0.5 \pm 0.18$ a.u, $\mathrm{p}=0.035$; TLR-9: $1.1 \pm 0.08$ a.u., $\mathrm{p}<0.001)$. (Figure $2 \mathrm{~A}, \mathrm{~B})$ 
VKC in the quiescent phase showed significant decrease of conjunctival TLR- 4 when compared with healthy controls $(p=0.010)$ while TLR-9 was significantly increased $(p=0.025)$. VKC group $R$ showed significant decrease of TLR-4 $(\mathrm{p}=0.005)$ when compared with healthy subjects while TLR-9 did not show significant changes.

In patients with VKC, the higher papillary reaction score was significantly correlated with the lower expression of tear sCD14 ( $\mathrm{p}=0.005, \mathrm{R}=-0.779)$, and of conjunctival CD14 ( $\mathrm{p}=0.049, \mathrm{R}=-0.668)$, TLR-4 ( $\mathrm{p}=0.015$, $\mathrm{R}=-0.850)$ and TLR-9 $(\mathrm{p}=0.001, \mathrm{R}=-0.891)$. Conjunctival hyperemia scores were also significantly correlated with tear sCD14 expression ( $\mathrm{p}=0.044, \mathrm{R}=-0.767)$.

No significant difference were found between patients with vs without other allergic diseases (tear sCD14: $0.63 \pm 0.29$ a.u vs $0.75 \pm 0.36$ a.u; conjunctival CD14: $0.75 \pm 0.34$ a.u vs $0.79 \pm 0.37$ a.u, TLR-4: $0.43 \pm 0.30$ a.u vs $0.38 \pm 0.22$ a.u, TLR-9: $0.88 \pm 0.42$ a.u vs $0.82 \pm 0.35$ a.u; respectively)

Six out of nine patients in the active group were treated with topical Hydrocortisone 4 times daily and were evaluated after 7 days. All patients showed improvement of signs and symptoms, with absence of conjunctival hyperemia and corneal involvement and mild to absent ocular symptoms. With except of tear sCD14 $(0.48 \pm 0.17$ a.u vs $0.51 \pm 0.16$ a.u $)$, all the biological parameter evaluated showed decrease of conjunctival expression however, only TLR-4 reached significant values when compared with baseline (TLR4: 0.18 \pm 0.11 a.u vs $0.09 \pm 0.03$ a.u, p=0.035; CD14: $0.46 \pm 0.1$ a.u vs $0.29 \pm 0.17$ a.u, TLR-9: $0.5 \pm 0.06$ a.u vs 0.31 \pm 0.13 ). (Figure 3)

\section{Discussion}

In this study, we demonstrated that CD14, TLR4 and TLR-9 are involved in ocular surface inflammatory flare-ups in patients with VKC. Specifically, tear sCD14 and conjunctival epithelium CD14 expression were decreased in patients with VKC suggesting that CD14 plays a potential protective role on the development of inflammatory reaction. In fact, it has been clearly demonstrated that CD14 modulates immune response to microbial products via TLRs, and recent evidence extended its role in the development of the allergic reaction. ${ }^{15,}{ }^{26}$ Although the role of CD14 in the pathogenesis of allergic diseases has not yet been completely understood, it has been hypothesized that CD14 is involved in atopy susceptibility. ${ }^{26}$ Several studies demonstrated that CD14 binding with LPS stimulates cytokine release through TLRs' signalling, and deviates the adaptive immune reaction toward a Th1 response and consequent Th2 suppression. ${ }^{12,13,27,28}$ As a consequence, alterations in the CD14 pathway may influence Th1/Th2 balance and may induce a switch toward atopy. ${ }^{29}$ In a paediatric population, an association between circulating sCD14 levels and low IL-4 response has been reported. ${ }^{30,}{ }^{31}$ Moreover, sCD14 has been shown to interact with B cells by inhibiting IL-6 and IgE production. ${ }^{32}$ It has been also demonstrated that during acute asthma attacks in children, plasma sCD14 levels were inversely correlated with asthma severity, suggesting that the expression of circulating sCD14 could have a protective effect in the development of asthma attacks. ${ }^{33,} 34$

Accordingly, VKC is characterized by infiltration of Th2 cells, eosinophils and mast cells and by the release of Th2 cytokines including IL-4, IL-5, IL10, TNF-alpha and IL- $13 .{ }^{35}$ In vitro studies showed that IL-4 and IL-13 inhibit sCD14 release in monocyte, and macrophage cultures ${ }^{36,37}$ Based on this evidence, we may hypothesize that the decrease of ocular surface CD14 expression observed in VKC patients may be an epiphenomenon of the inflammatory reaction during active VKC. This hypothesis may be supported by the significant correlation between the severity of conjunctival hyperaemia and the decrease of tear sCD14. However, after seven days of topical corticosteroid treatment and resolution of the ocular inflammatory reaction, we did not find significant changes of expression of tear sCD14 and conjunctival CD14. This result may support the alternative hypothesis that the lower expression of ocular surface CD14 is associated with the higher risk to develop recrudescence of VKC inflammation. On the other hand, ocular surface CD14 expression may require longer time to normalize after topical corticosteroid treatments, as suggested by the observation that VKC patients in the quiescent phase showed CD14 expression levels similar to healthy subjects. ${ }^{38}$

Our results also showed that conjunctival epithelium expression of TLR-4 and TLR-9 decreased during active 
inflammation of VKC, suggesting that TLRs may contribute to the inhibition of development of the allergic reaction. This finding is in line with previous studies, which showed that TLR-4 and TLR-9 were reduced in epithelial and inflammatory cells in allergic rhinitis. ${ }^{39}, 40$ The protective role of TLR-9 against allergic inflammation is supported by several studies. ${ }^{40,}{ }^{41}$ In addition, it has been reported that TLR-9 expression was decreased in conjunctival biopsies of VKC patients in the active phase. ${ }^{9,}{ }^{10}$ Conversely, the role of TLR-4 in VKC should be further clarified. Our results showed that conjunctival epithelium TLR-4 expression was decreased while it has been reported that immune cells infiltrating the conjunctiva of VKC patients showed increased expression of TLR-4. ${ }^{10}$ These findings suggest a possible different role played by resident cells (conjunctival epithelium) and the infiltrating immune cells in the development of allergic reaction in VKC. The active role of conjunctival epithelium in the development of allergic reaction has been demonstrated. ${ }^{24}$ In fact, it is known that environmental factors, including microbial agents or hormonal influence may induce changes of conjunctival epithelium expression of TLRs by which may predispose to atopic conditions. ${ }^{42-44}$ On the other hand, the hypothesis of a protective role of CD14 and TLR-4 in the development of ocular allergic reaction is supported by the results of an experimental study showing that that LPS interaction with TLR- 4 was able to decrease Th2 response through TLR-4 signalling. ${ }^{18,44}$ In addition, Iovieno et al. showed that administration of topical Lactobacillus was effective in reducing inflammatory reaction in VKC patients and that the clinical improvement was associated with decrease of TLR- 4 conjunctival expression. ${ }^{45}$ Accordingly, our results demonstrated that topical steroid treatment in VKC induced significant inhibition of TLR-4 conjunctival expression.

This study showed that ocular surface decreased expression of CD14 and its ligands TLR-4 and 9 may foster the development of allergic reaction in VKC, suggesting tevaluate the potential therapeutic role of agents targeting these receptors.

\section{References}

1. Bonini S, Bonini S, Lambiase A, Marchi S, Pasqualetti P, Zuccaro O, et al. Vernal keratoconjunctivitis revisited: a case series of 195 patients with long-term followup. Ophthalmology 2000; 107:1157-63.

2. Sacchetti M, Abicca I, Bruscolini A, Cavaliere C, Nebbioso M, Lambiase A. Allergic conjunctivitis: current concepts on pathogenesis and management. J Biol Regul Homeost Agents 2018; 32:49-60.

3. Sacchetti M, Lambiase A, Mantelli F, Deligianni V, Leonardi A, Bonini S. Tailored approach to the treatment of vernal keratoconjunctivitis. Ophthalmology 2010; 117:1294-9.

4. Bonini S, Sacchetti M, Mantelli F, Lambiase A. Clinical grading of vernal keratoconjunctivitis. Curr Opin Allergy Clin Immunol 2007; 7:436-41.

5. Sacchetti M, Baiardini I, Lambiase A, Aronni S, Fassio O, Gramiccioni C, et al. Development and testing of the quality of life in children with vernal keratoconjunctivitis questionnaire. Am J Ophthalmol 2007; 144:557-63.

6. Bonini S, Lambiase A, Sgrulletta R, Bonini S. Allergic chronic inflammation of the ocular surface in vernal keratoconjunctivitis. Curr Opin Allergy Clin Immunol 2003; 3:381-7.

7. Maggi E, Biswas P, Del Prete G, Parronchi P, Macchia D, Simonelli C, et al. Accumulation of Th-2-like helper T cells in the conjunctiva of patients with vernal conjunctivitis. J Immunol 1991; 146:1169-74.

8. Lambiase A, Micera A, Sacchetti M, Mantelli F, Bonini S. Toll-like receptors in ocular surface diseases: overview and new findings. Clin Sci (Lond) 2011; 120:441-50.

9. Micera A, Stampachiacchiere B, Normando EM, Lambiase A, Bonini S, Bonini S. Nerve growth factor modulates toll-like receptor (TLR) 4 and 9 expression in cultured primary VKC conjunctival epithelial cells. Mol Vis 2009; 15:2037-44.

10. Bonini S, Micera A, Iovieno A, Lambiase A, Bonini S. Expression of Toll-like receptors in healthy and allergic conjunctiva. Ophthalmology 2005; 112:1528; discussion 48-9. 
11. Akira S, Takeda K, Kaisho T. Toll-like receptors: critical proteins linking innate and acquired immunity. Nat Immunol 2001; 2:675-80.

12. Baumann CL, Aspalter IM, Sharif O, Pichlmair A, Bluml S, Grebien F, et al. CD14 is a coreceptor of Toll-like receptors 7 and 9. J Exp Med 2010; 207:2689-701.

13. Verhasselt V, Buelens C, Willems F, De Groote D, Haeffner-Cavaillon N, Goldman M. Bacterial lipopolysaccharide stimulates the production of cytokines and the expression of costimulatory molecules by human peripheral blood dendritic cells: evidence for a soluble CD14-dependent pathway. J Immunol 1997; 158:2919-25.

14. Schumann RR. Function of lipopolysaccharide (LPS)-binding protein (LBP) and CD14, the receptor for LPS/LBP complexes: a short review. Res Immunol 1992; 143:11-5.

15. Vercelli D, Baldini M, Stern D, Lohman IC, Halonen M, Martinez F. CD14: a bridge between innate immunity and adaptive IgE responses. J Endotoxin Res 2001; 7:45-8.

16. Baldini M, Vercelli D, Martinez FD. CD14: an example of gene by environment interaction in allergic disease. Allergy 2002; 57:188-92.

17. Leung TF, Tang NL, Wong GW, Fok TF. CD14 and toll-like receptors: potential contribution of genetic factors and mechanisms to inflammation and allergy. Curr Drug Targets Inflamm Allergy 2005; 4:169-75.

18. Chung SH, Choi SH, Cho KJ, Joo CK. Toll-like receptor 4 signalling attenuates experimental allergic conjunctivitis. Clin Exp Immunol 2011; 164:275-81.

19. Blais DR, Vascotto SG, Griffith M, Altosaar I. LBP and CD14 secreted in tears by the lacrimal glands modulate the LPS response of corneal epithelial cells. Invest Ophthalmol Vis Sci 2005; 46:4235-44.

20. Zicari AM, Capata G, Nebbioso M, De Castro G, Midulla F, Leonardi L, et al. Vernal Keratoconjunctivitis: an update focused on clinical grading system. Ital J Pediatr 2019; 45:64.

21. Wolffsohn JS, Arita R, Chalmers R, Djalilian A, Dogru M, Dumbleton K, et al. TFOS DEWS II Diagnostic Methodology report. Ocul Surf 2017; 15:539-74.

22. Sacchetti M, Micera A, Lambiase A, Speranza S, Mantelli F, Petrachi G, et al. Tear levels of neuropeptides increase after specific allergen challenge in allergic conjunctivitis. Mol Vis 2011; 17:47-52.

23. Sacchetti M, Lambiase A, Cortes M, Sgrulletta R, Bonini S, Merlo D, et al. Clinical and cytological findings in limbal stem cell deficiency. Graefes Arch Clin Exp Ophthalmol 2005; 243:870-6.

24. Sacchetti M, Segatto M, Bruscolini A, Abicca I, Cavaliere C, Lambiase A. Changes of NGF pathway in allergic rhinoconjunctivitis: A conjunctival allergen challenge study. Allergy 2019; 74:605-7.

25. da Rocha JT, Trapani L, Segatto M, La Rosa P, Nogueira CW, Zeni G, et al. Molecular effects of diphenyl diselenide on cholesterol and glucose cell metabolism. Curr Med Chem 2013; 20:4426-34.

26. Lodrup Carlsen KC, Granum B. Soluble CD14: role in atopic disease and recurrent infections, including otitis media. Curr Allergy Asthma Rep 2007; 7:436-43.

27. Macatonia SE, Hosken NA, Litton M, Vieira P, Hsieh CS, Culpepper JA, et al. Dendritic cells produce IL-12 and direct the development of Th1 cells from naive CD4+ T cells. J Immunol 1995; 154:5071-9.

28. Ulevitch RJ, Tobias PS. Receptor-dependent mechanisms of cell stimulation by bacterial endotoxin. Annu Rev Immunol 1995; 13:437-57.

29. Martinez FD. CD14, endotoxin, and asthma risk: actions and interactions. Proc Am Thorac Soc 2007; 4:221-5.

30. Rey Nores JE, Bensussan A, Vita N, Stelter F, Arias MA, Jones M, et al. Soluble CD14 acts as a negative regulator of human T cell activation and function. Eur J Immunol 1999; 29:265-76. 
31. Baldini M, Lohman IC, Halonen M, Erickson RP, Holt PG, Martinez FD. A Polymorphism* in the 5' flanking region of the CD14 gene is associated with circulating soluble CD14 levels and with total serum immunoglobulin E. Am J Respir Cell Mol Biol 1999; 20:976-83.

32. Arias MA, Rey Nores JE, Vita N, Stelter F, Borysiewicz LK, Ferrara P, et al. Cutting edge: human B cell function is regulated by interaction with soluble CD14: opposite effects on IgG1 and IgE production. J Immunol 2000; 164:3480-6.

33. Martin AC, Laing IA, Khoo SK, Zhang G, Rueter K, Teoh L, et al. Acute asthma in children: Relationships among CD14 and CC16 genotypes, plasma levels, and severity. Am J Respir Crit Care Med 2006; 173:617-22.

34. Zhou T, Huang X, Ma J, Zhou Y, Liu Y, Xiao L, et al. Association of plasma soluble CD14 level with asthma severity in adults: a case control study in China. Respir Res 2019; 20:19.

35. Leonardi A, Sathe S, Bortolotti M, Beaton A, Sack R. Cytokines, matrix metalloproteases, angiogenic and growth factors in tears of normal subjects and vernal keratoconjunctivitis patients. Allergy 2009; 64:710-7.

36. Landmann R, Fisscher AE, Obrecht JP. Interferon-gamma and interleukin-4 down-regulate soluble CD14 release in human monocytes and macrophages. J Leukoc Biol 1992; 52:323-30.

37. Cosentino G, Soprana E, Thienes CP, Siccardi AG, Viale G, Vercelli D. IL-13 down-regulates CD14 expression and TNF-alpha secretion in normal human monocytes. J Immunol 1995; 155:3145-51.

38. Wang ZR, Wang Q, Sui Y, Zhang ZL, Jia FJ, Fan J, et al. Dexamethasone alleviates allergic asthma immature rat through Toll like receptor 4. Eur Rev Med Pharmacol Sci 2018; 22:184-9.

39. Lauriello M, Micera A, Muzi P, Di Rienzo Businco L, Bonini S. TLR4 and TLR9 Expression in Different Phenotypes of Rhinitis. Int J Otolaryngol 2012; 2012:925164.

40. Bergougnan C, Dittlein DC, Hummer E, Riepl R, Eisenbart S, Bock D, et al. Physical and immunological barrier of human primary nasal epithelial cells from non-allergic and allergic donors. World Allergy Organ J 2020; 13:100109.

41. Volpi C, Fallarino F, Pallotta MT, Bianchi R, Vacca C, Belladonna ML, et al. High doses of CpG oligodeoxynucleotides stimulate a tolerogenic TLR9-TRIF pathway. Nat Commun 2013; 4:1852.

42. Rakoff-Nahoum S, Paglino J, Eslami-Varzaneh F, Edberg S, Medzhitov R. Recognition of commensal microflora by toll-like receptors is required for intestinal homeostasis. Cell 2004; 118:229-41.

43. Rodriguez D, Keller AC, Faquim-Mauro EL, de Macedo MS, Cunha FQ, Lefort J, et al. Bacterial lipopolysaccharide signaling through Toll-like receptor 4 suppresses asthma-like responses via nitric oxide synthase 2 activity. J Immunol 2003; 171:1001-8.

44. Dabbagh K, Dahl ME, Stepick-Biek P, Lewis DB. Toll-like receptor 4 is required for optimal development of Th2 immune responses: role of dendritic cells. J Immunol 2002; 168:4524-30.

45. Iovieno A, Lambiase A, Sacchetti M, Stampachiacchiere B, Micera A, Bonini S. Preliminary evidence of the efficacy of probiotic eye-drop treatment in patients with vernal keratoconjunctivitis. Graefes Arch Clin Exp Ophthalmol 2008; 246:435-41.

Table 1. Demographic and clinical characteristics of patients included in the study.

\begin{tabular}{lllll}
\hline & $\begin{array}{l}\text { All patients with } \\
\text { VKC (N=18) }\end{array}$ & $\begin{array}{l}\text { VKC group A } \\
(\mathbf{N = 9})\end{array}$ & $\begin{array}{l}\text { VOC group Q } \\
(\mathbf{N}=\mathbf{5})\end{array}$ & $\begin{array}{l}\text { VKC group R } \\
(\mathbf{N}=\mathbf{4})\end{array}$ \\
\hline $\begin{array}{l}\text { Gender }(\mathbf{N}) \\
\begin{array}{l}\text { Male Female } \\
\text { Age (years) }\end{array}\end{array}$ & 153 & 72 & 41 & 40 \\
Mean \pm SD & $10.7 \pm 5.7$ & $9 \pm 2.3$ & $8.5 \pm 4.4$ & $22 \pm 5$
\end{tabular}




\begin{tabular}{|c|c|c|c|c|}
\hline & $\begin{array}{l}\text { All patients with } \\
\text { VKC }(N=18)\end{array}$ & $\begin{array}{l}\text { VKC group A } \\
(\mathrm{N}=9)\end{array}$ & $\begin{array}{l}\text { VOC group } Q \\
(\mathrm{~N}=5)\end{array}$ & $\begin{array}{l}\text { VKC group } \mathrm{R} \\
(\mathrm{N}=4)\end{array}$ \\
\hline $\begin{array}{l}\text { Positive skin } \\
\text { prick test }(\mathrm{N})\end{array}$ & 11 & 6 & 3 & 2 \\
\hline $\begin{array}{l}\text { Tarsal VKC } \\
\text { Limbal VKC } \\
\text { Mixed VKC }\end{array}$ & 1611 & 711 & 500 & 400 \\
\hline $\begin{array}{l}\text { Conjunctival } \\
\text { hyperemia } \\
\text { score } 0123\end{array}$ & 9153 & 0153 & 5000 & 4000 \\
\hline $\begin{array}{l}\text { Conjunctival } \\
\text { secretion score } \\
0123\end{array}$ & 10521 & 2421 & 4100 & 4000 \\
\hline $\begin{array}{l}\text { Conjunctival } \\
\text { papillary } \\
\text { reaction score } 0 \\
123\end{array}$ & 0495 & 0045 & 0230 & 0220 \\
\hline $\begin{array}{l}\text { Cornea staining } \\
\text { (Oxford scale) } 0 \\
12345\end{array}$ & 953100 & 053100 & $\begin{array}{llllll}5 & 0 & 0 & 0 & 0 & 0\end{array}$ & 40000000 \\
\hline $\begin{array}{l}\text { Itching score } 0 \\
\begin{array}{l}123\end{array}\end{array}$ & 7542 & 0342 & 3200 & 4000 \\
\hline $\begin{array}{l}\text { Tearing score } 0 \\
123\end{array}$ & 9441 & 0441 & 5000 & 4000 \\
\hline $\begin{array}{l}\text { Photophobia } \\
\text { score } 0123\end{array}$ & 9351 & 0351 & 5000 & 4000 \\
\hline
\end{tabular}

N:number, SD: standard deviation; Group A: active VKC; group Q: quiescent VKC; group R: recovered VKC.

\section{Figure legends}

Figure 1. Patients with VKC in the active phase (group A) showed significant decrease of tear sCD14 and conjunctival CD14 expression when compared with healthy subjects and with patients with VKC in the quiescent phase (group Q) and after VKC recovery (group R). * = statistical significant vs healthy group; § $=$ statistical significant vs VKC in the quiescent phase (group Q); C = statistical significant vs VKC recovery (group R).

Figure 2 Changes of expression of conjunctival TLR-4 and TLR-9 in patients with VKC in the active (A) and quiescent $(\mathrm{Q})$ phases of the disease and after $\mathrm{VKC}$ recovery $(\mathrm{R})$ compared with healthy controls. ${ }^{*}=$ statistical significant vs healthy group; $\S=$ statistical significant vs VKC in the quiescent phase (group Q); $\mathrm{C}=$ statistical significant vs VKC recovery (group R).

Figure 3 Changes of expression of tear sCD14 and conjunctival CD14, TLR-4 and TLR-9 in patients with VKC in the active phase, 7 days after topical treatment with Hydrocortisone eye drops. ${ }^{*}=$ statistical significant vs baseline. 

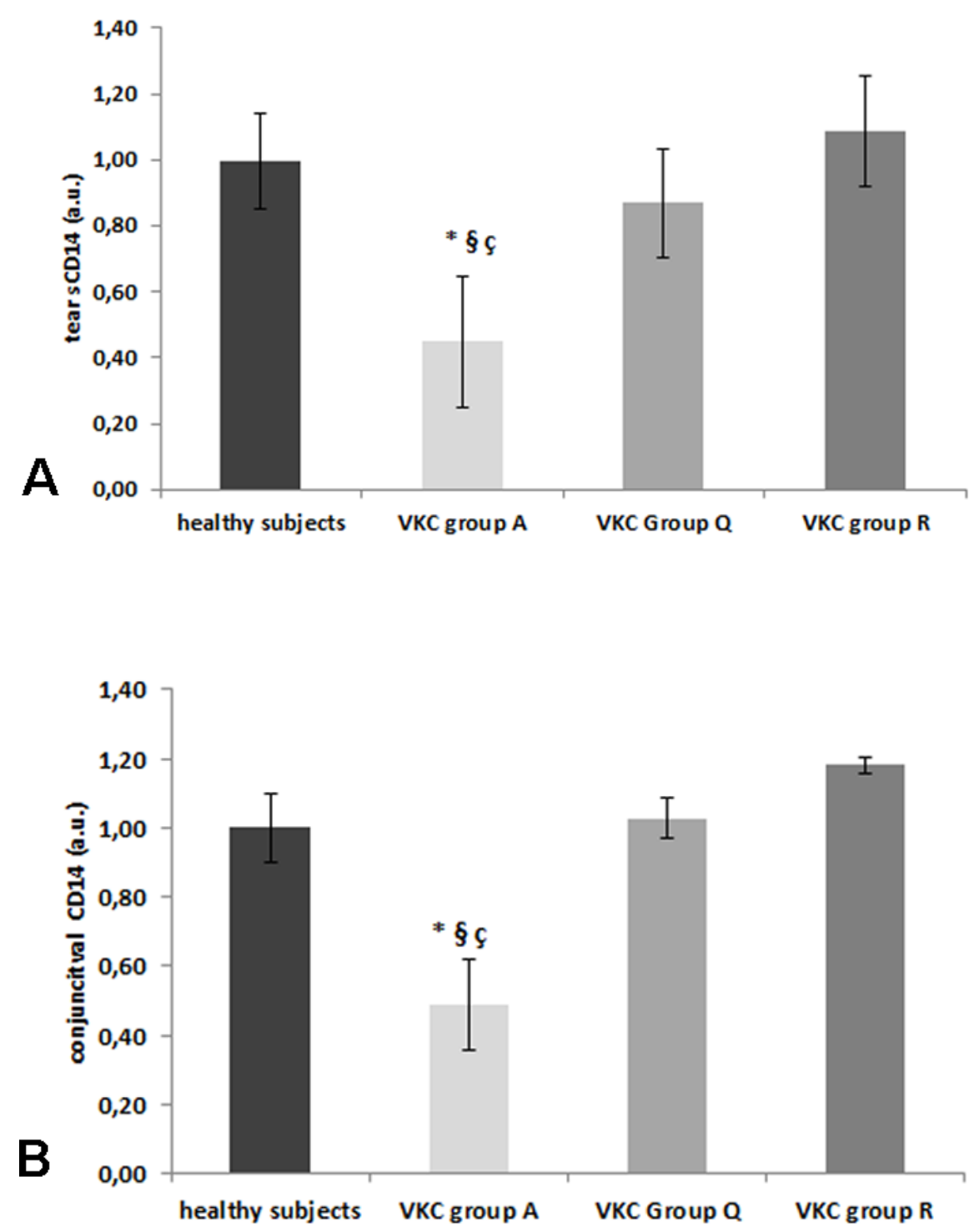

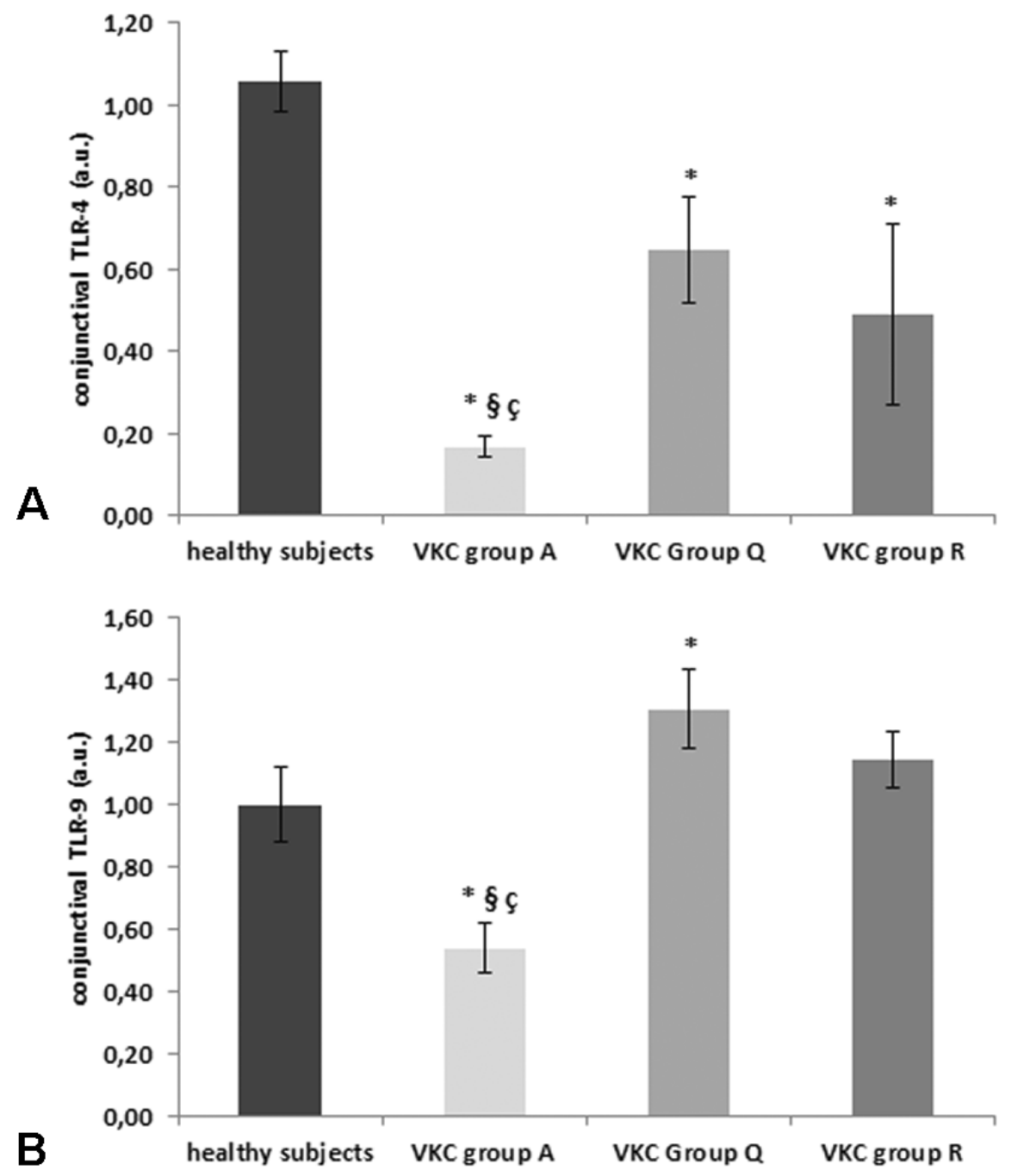


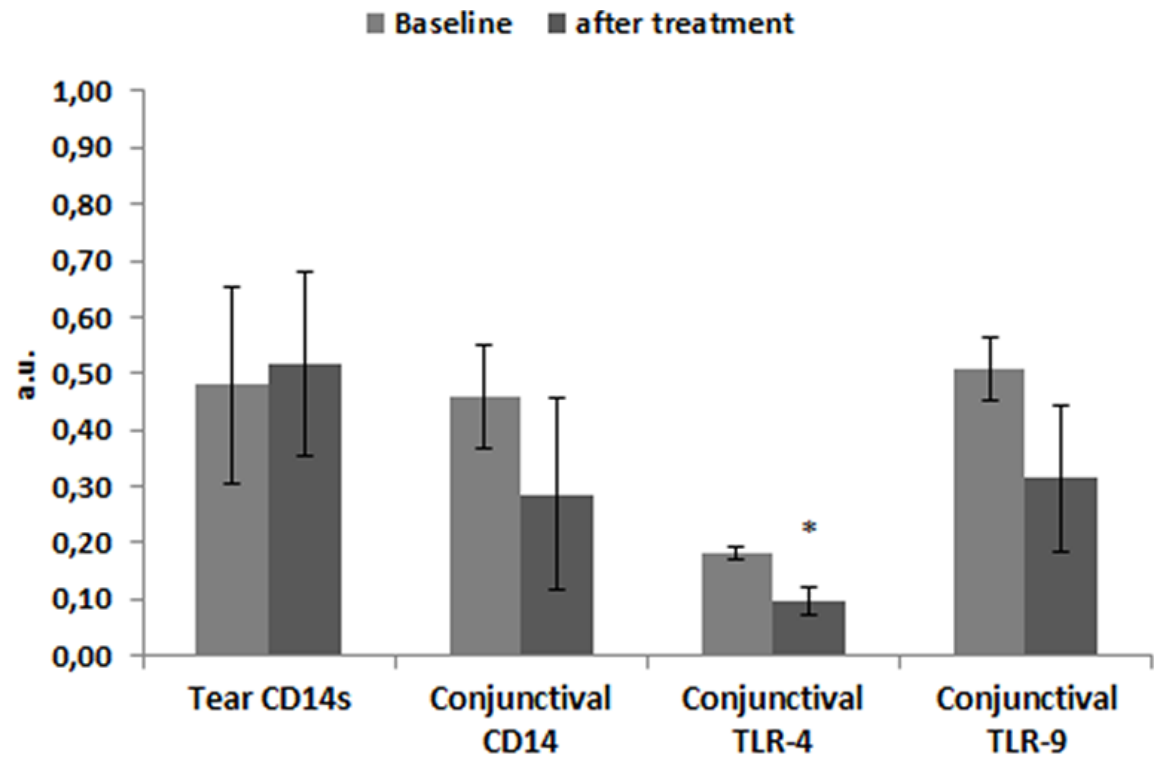

